\title{
BIASED RECOGNITION OF HAPPY FACIAL EXPRESSIONS IN SOCIAL ANXIETY*
}

By: Paul J Silvia, Wesley D Allan, Daniel L Beauchamp, Emily L Maschauer, and Jamie O Workman

Silvia, P. J., Allan, W. D., Beauchamp, D. L., Maschauer, E. L., \& Workman, J. O. (2006). Biased recognition of happy facial expressions in social anxiety. Journal of Social and Clinical Psychology, 25, 585-602.

Made available courtesy of Guilford Press: http://www.guilford.com/cgi-

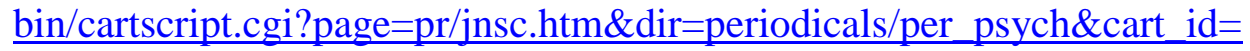

\section{***Note: Figures may be missing from this format of the document}

\begin{abstract}
:
Recognizing emotional expressions is central to understanding the feelings and intentions of other people. Little is known about how social anxiety affects the recognition of emotional expressions. Recent research finds a recognition advantage for happy expressions over negative expressions. In two experiments, social anxiety moderated the recognition advantage of happy faces. People low and high in social anxiety recognized sad faces (Experiment 1) and angry faces (Experiment 2) equally quickly, but people high in social anxiety took longer to recognize happy faces. Both groups showed a significant recognition advantage for happy faces, although the advantage was at least twice as large in the low social-anxiety group. The discussion focuses on mechanisms connecting social anxiety to face processing and on the role of expression recognition in other emotionalprocessing biases.

\section{Article:}

Recognizing emotional expressions is central to understanding the feelings and intentions of other people. Little is known about how social anxiety affects the recognition of emotional expressions. Recent research finds a recognition advantage for happy expressions over negative expressions. In two experiments, social anxiety moderated the recognition advantage of happy faces. People low and high in social anxiety recognized sad faces (Experiment 1) and angry faces (Experiment 2) equally quickly, but people high in social anxiety took longer to recognize happy faces. Both groups showed a significant recognition advantage for happy faces, although the advantage was at least twice as large in the low social-anxiety group. The discussion focuses on mechanisms connecting social anxiety to face processing and on the role of expression recognition in other emotionalprocessing biases.
\end{abstract}

Social anxiety is characterized by persistent fears of interacting with other people, performing before others, and being observed, scrutinized, and evaluated (Clark \& Wells, 1995; Leary \& Kowalski, 1995). Social anxiety is viewed as a continuum, ranging from social fearlessness to subclinical social anxiety to clinical levels of social phobia (McNeil, 2001; Rapee \& Heimberg, 1997). At subclinical levels, social anxiety is relatively common-approximately $20 \%$ of people report having irrational social fears (Furmark et al., 1999). Lifetime prevalence of clinical social anxiety is approximately $5 \%$ for men and $10 \%$ for women (Wittchen, Stein, \& Kessler, 1999), although some estimates place the lifetime prevalence at around 13 to 16\% (Kessler, McGonagle, \& Zhao, 1994; Wacker, Müllejans, Klein, \& Battegay, 1992).

Cognitive theories of social anxiety contend that information-processing biases are central to the disorder (Clark et al., 2003; Clark \& Wells, 1995; Foa, Franklin, \& Kozak, 2001; Rapee \& Heimberg, 1997; Turk, Lerner, Heimberg, \& Rapee, 2001). Biases in attention, memory, and reasoning are thought to exacerbate and maintain social anxiety. Consistent with the claims of cognitive models, research has discovered many biases in information processing in clinical and subclinical samples, such as negative interpretations of ambiguous events, appraisals of social situations as dangerous, vigilance for threatening information, and excessive self-

\footnotetext{
* This research was presented at the 2004 meeting of the Society of Southeastern Social Psychologists, Clemson, SC.
} 
focused attention (see Amir \& Foa, 2001; Foa, Franklin, Perry, \& Herbert, 1996; Heinrichs \& Hofmann, 2001; Spurr \& Stopa, 2002).

Many of social anxiety's cognitive biases involve processing emotional expressions. Facial expressions of emotion are powerful sources of social information (Darwin, 1872/1998; Ekman, 1993; Izard, 1971)-positive and negative emotional expressions quickly convey social messages (Keltner \& Ekman, 2000). During social interactions, people gain much of their information about the feelings and intentions of others through emotional expressions, such as the liking and approval expressed by happy faces, the hostility expressed by angry faces, and the rejection expressed by disgusted and contemptuous faces. In a recent review, Heinrichs and Hofmann (2001) noted a need for more research on how socially anxious people process faces, because positive and negative facial expressions are more ecologically valid signals than are more widely studied stimuli (e.g., positive and negative words).

To date, a small literature has investigated biased processing of facial expressions in social anxiety. Socially anxious people (1) direct their attention to angry, threatening faces instead of happy or neutral faces (Mogg \& Bradley, 2002; Mogg, Philippot, \& Bradley, 2004); (2) detect threatening faces faster than happy faces in visual search tasks (Gilboa-Schechtman, Foa, \& Amir, 1999); (3) avoid looking at emotional faces when nonsocial stimuli can be viewed instead (Mansell, Clark, Ehlers, \& Chen, 1999); (4) display biased memory for faces displaying angry and happy emotions (D'Argembeau, Van der Linden, Etienne, \& Comblain, 2003; Lundh \& Öst, 1996); (5) do not report increased social efficacy following a conversation with a partner displaying positive emotions (e.g., maintaining eye contact, nodding), instead seemingly discounting the interaction (Wallace \& Alden, 1997); and (6) may show biased descriptions of the emotions presented on emotional faces (Merckelbach, van Hout, van den Hout, \& Mersch, 1989; Philippot \& Douilliez, 2005).

What do these emotional-processing biases have in common? One cognitive process-the recognition of emotional expressions-is involved in each of these biases. For example, to direct attention to an angry instead of a neutral face, one must first recognize the emotion on each face. To show biased recall for faces showing certain emotions, one must have first recognized the emotion on the face to encode it with the face's identity. When attention is directed away from emotional faces, the emotional expression must first be decoded. Although the recognition of emotional expressions subserves several well-known biases in social anxiety, little is known about how socially anxious people recognize emotional expressions. Only a handful of experiments have explored whether social anxiety affects this fundamental aspect of emotional processing. One experiment found that children with clinical social phobia took longer to recognize all emotional faces (Melfsen \& Florin, 2002), relative to nonphobic children. It is unclear, however, whether this result reflected an across-the-board deficit in emotion recognition or simply a disruptive effect of anxiety on performance. Another experiment found that socially anxious adults had a negative response bias when classifying faces as neutral or negative (Winton, Clark, \& Edelmann, 1995). Response times were not recorded, however, thus leaving open the question of whether socially anxious people recognized some expressions faster than others.

These two experiments are important early steps, yet they have some limitations. First, in both experiments, the faces were presented for $60 \mathrm{~ms}$ and followed by a pattern mask. It takes up to $170 \mathrm{~ms}$ to form a detailed structural representation of a face (Adolphs, 2002), so responses to brief-and-masked presentations will be overly influenced by response biases (such as the negative response bias found by Winton et al., 1995). Second, neither experiment distinguished between types of negative expressions. Participants were asked to give the same response to different negative expressions (e.g., anger, fear, disgust, contempt, and sadness). Recent research, however, shows that people do not process all negative emotions alike; angry expressions are particularly central to face processing (Fox et al., 2000; Lundqvist, Esteves, \& Ohman, 1999; Tipples, Atkinson, $\&$ Young, 2002). Thus, these experiments do not assess potential differences between negative emotions.

\section{RECOGNIZING EMOTIONAL EXPRESSIONS}

People recognize emotional expressions automatically, meaning that they identify a face's emotional expression quickly, unintentionally, and effortlessly (Bruce \& Young, 1986; Haxby, Hoffman, \& Gobbini, 2000; Stenberg, 
Wiking, \& Dahl, 1998). Like many automatic processes, the process of recognizing an emotional expression is highly conceptual (see Adolphs, 2002). Emotions cannot be recognized solely by perceiving visual features of the face. The retrieval and application of conceptual knowledge of emotions is necessary for understanding the face's emotional meaning and labeling the expression (Adolphs, 2002). Upon forming a structural representation of a face (Bruce \& Young, 1986), people must retrieve higher-order conceptual information to label the perceptual representation as a "happy face," "angry face," or "sad face." Understanding the central role of conceptual knowledge in expression recognition is pivotal to appreciating how biases in expression recognition can emerge.

The present experiments take as their starting point recent research on the recognition of positive and negative facial expressions (Leppänen \& Hietanen, 2004; Leppänen, Tenhunen, \& Hietanen, 2003). Many experiments find a happy-face recognition advantage, in which people recognize happy faces faster than negative facial expressions (Feyereisen, Malet, \& Martin, 1986; Kirita \& Endo, 1995; Leppänen \& Hietanen, 2003). This effect is not due to simple differences in low-level face features; significant happy-face advantages appear for schematic faces that control for an expression's featural complexity (Kirita \& Endo, 1995; Leppänen \& Hietanen, 2004, Experiment 2). Instead, it reflects differences in how quickly people can retrieve and apply conceptual knowledge to the perceptual representation of the face. For example, activating positive emotional information boosts the advantage for happy faces, whereas activating disgusting emotional information causes an advantage for disgusted faces (Leppänen \& Hietanen, 2003, Experiment 2).

Research on the happy-face recognition advantage suggests that social anxiety could impair the recognition of happy facial expressions. As noted earlier, recognizing facial expressions requires applying conceptual knowledge about others and emotions (Adolphs, 2002). Based on their body of research, Leppänen and Hietanen (2004) contended that the advantage for happy faces resulted from "a tendency to form positively biased hypotheses about reality and, especially, about other people" (pp. 27-28). If positive information about other people and their emotions is less chronically accessible or less easily retrieved, then it will take longer to apply emotional knowledge to the perceptual representation of the face. This will manifest in the speed of recognizing an emotion. People high in social anxiety view other people as critical and threatening (Rapee \& Heimberg, 1997; Turk et al., 2001). This bias should slow down the recognition of positive facial expressions, given that signals of acceptance and reward are inconsistent with the expected emotions and intentions of others. Thus, the different socioemotional knowledge held by people high and low in social anxiety will translate into differences in the recognition of emotional expressions.

\section{THE PRESENT EXPERIMENTS}

The present experiments examined whether social anxiety biases the recognition of emotional expressions. In each experiment, people completed a two-choice recognition task in which they had to classify emotional expressions as quickly as possible. To maximize the ecological validity of the findings, we used images of real faces displaying prototypical facial expressions (Ekman \& Friesen, 1976) instead of iconic or schematic emotional faces. The first experiment compared happy and sad faces; the second experiment compared happy and angry faces. In each experiment, we expected social anxiety to reduce the happy-face recognition advantage. It was unclear at the outset if this would manifest as a smaller advantage for happy faces, a lack of an advantage, or even an advantage for negative emotional expressions.

\section{EXPERIMENT 1}

Experiment 1 compared the recognition of happy faces and sad faces. Past research with general-population samples has found a happy-face advantage relative to sad faces (Leppänen \& Hietanen, 2004; Leppanen, Milders, Bell, Terriere, \& Hietanen, 2004). Relative to angry faces, sad faces have not received as much attention in research on general anxiety and social anxiety. Recent research finds that sad faces have many of the same effects as angry faces (see Silvia \& Warburton, 2006). Sad faces are detected more efficiently in visual-search paradigms (Eastwood, Smilek, \& Merikle, 2001, 2003), and they seem to influence the control of attention (Fenske \& Eastwood, 2003). Thus, it seems worthwhile to contrast the recognition of happy and sad faces. 


\section{METHOD}

\section{Participants and Design}

A total of 30 undergraduate students (25 women and 5 men) enrolled in General Psychology at the University of North Carolina at Greensboro participated and received credit toward a research option. Women and men were evenly distributed in the low (12 women, 3 men) and high (13 women, 2 men) social-anxiety conditions.

\section{Procedure}

Assessment of Social Anxiety. Participants were selected from a larger sample based on their social anxiety scores on Mattick and Clarke's (1998) Social Interaction Anxiety Scale (SIAS) and Social Phobia Scale (SPS). Previous research has established that these scales have good reliability and validity in both clinical and subclinical samples (Heimberg, Mueller, Holt, Hope, \& Liebowitz, 1992; Herbert, Rheingold, \& Brandsma, 2001; Osman, Gutierrez, Barrios, Kopper, \& Chiros, 1998). Responses to the Social Interaction Anxiety Scale and the Social Phobia Scale were computed by averaging each scale's items, after reverse-scoring as required. Following past research (e.g., Kashdan, 2002; Kashdan \& Roberts, 2004), a single social anxiety score was then computed by standardizing each scale and averaging the values. A large sample $(n=145)$ completed these scales, which were completed on 7-point Likert scales. People scoring in the upper and lower thirds of the distribution were eligible for the experiment. People in the high social-anxiety condition had elevated scores on these scales (SIAS M = 3.96, SPS M = 3.69, on 7-point scales) relative to people in the low-social-anxiety condition (SIAS M = 1.55, SPS M =1.67), but their scores were in the subclinical range.

Recognition Task. Participants were told that the experiment concerned how people perceive and process faces. They completed a computer-based recognition task that assessed the relative speed of recognizing happy and sad faces. Four happy expressions and four sad expressions were selected from the standard Ekman and Friesen (1976) set. The eight expressions consisted of one happy and one sad expression for two male and two female actors. Restricting the set of faces to four individuals reduces the variance due to idiosyncratic face features associated with processing the identity of a face (Bruce \& Young, 1986).

The timing parameters of the emotion-recognition task were modeled after past research on the happy-face recognition advantage (see Leppänen \& Hietanen, 2003, 2004). Each trial began with a fixation cross followed by a face. The face appeared in the center of the screen for $200 \mathrm{~ms}$, which is sufficient for a detailed structural representation of the face to be formed (Adolphs, 2002). A blank screen appeared and remained until the participant gave a response. Thus, response latencies were measured starting from the offset of the face. After a brief practice period, participants completed 5 blocks of 16 trials, for a total of 80 trials (40 happy, $40 \mathrm{sad}$ ). The faces appeared in a different random order for each participant. Standard speed-accuracy instructions were given.

The presentation and timing were controlled by Superlab Pro (version 2.0.4). Participants responded with Cedrus RB-620 response pads, which measure key presses with a timing accuracy of 1 ms. Happy faces were mapped onto a green key, and sad faces were mapped onto a red key. 
TABLE 1. Effects of Social Anxiety on the Recognition of Happy and Sad Faces: Experiment 1

\begin{tabular}{|c|c|c|c|c|}
\hline & \multicolumn{2}{|c|}{ Low Social Anxiety } & \multicolumn{2}{|c|}{ High Social Anxiety } \\
\hline & Happy Faces & Sad Faces & Happy Faces & Sad Faces \\
\hline \multicolumn{5}{|c|}{ Response Times } \\
\hline$M$ & 305 & 347 & 330 & 348 \\
\hline$S D$ & 76.1 & 72.2 & 58.5 & 61.9 \\
\hline \multicolumn{5}{|c|}{ Errors } \\
\hline$M$ & 1.47 & .93 & 1.73 & .80 \\
\hline$S D$ & 1.06 & .96 & 1.94 & 1.08 \\
\hline
\end{tabular}

Note. Response times have been rounded to the nearest millisecond. They indicate response latencies from the offset of the faces, which appeared for $200 \mathrm{~ms} . n=15$ in each social-anxiety condition.

\section{RESULTS}

Data Treatment and Reduction

All incorrect responses in the expression-recognition task were deleted and scored as errors. Each participant's data were then screened for outliers, defined as values 3 standard deviations from each participant's mean value (Fox, Russo, Bowles, \& Dutton, 2001; Ratcliff, 1993). Effect sizes were computed with Minsize 2 (Morse, 1999).

\section{Recognizing Happy and Sad Faces}

In the sample as a whole, people recognized happy faces $(318 \mathrm{~ms})$ faster than sad faces ( $348 \mathrm{~ms})$, pairedsamples $\mathrm{t}(29)=4.97, \mathrm{p}<.001, \mathrm{~d}=.91$. This replicates past research (Leppänen \& Hietanen, 2003, 2004) and provides a basis for examining whether social anxiety moderates the recognition advantage for happy faces. A mixed-model analysis of variance (ANOVA) estimated the effect of social anxiety (low, high) and face type (happy, sad) on response latencies. This analysis revealed a significant main effect of face type, reflecting the advantage for happy faces, $\mathrm{F}(1,28)=27.5, \mathrm{p}<.001$, as well as a significant interaction, $\mathrm{F}(1,28)=4.31$, $\mathrm{p}<.047$. There was no main effect of social anxiety, $\mathrm{F}<1$. The data are presented in Table 1; the pattern of means is shown in Figure 1.

Further analyses found that both groups showed a significant happy-face advantage. People low in social anxiety recognized happy faces faster than sad faces, paired-samples $t(14)=4.77, \mathrm{p}<.001, \mathrm{~d}=1.23$, with a difference of $42 \mathrm{~ms}$. People high in social anxiety also recognized happy faces faster than sad faces, pairedsamples $\mathrm{t}(14)=2.48, \mathrm{p}<.027, \mathrm{~d}=.64$; the difference between happy and sad faces was less than half as long $(18 \mathrm{~ms})$. The low social-anxiety group had a significantly larger happy-face advantage relative to the high social-anxiety group, $\mathrm{t}(28)=2.08, \mathrm{p}<.047, \mathrm{~d}=.76$. 


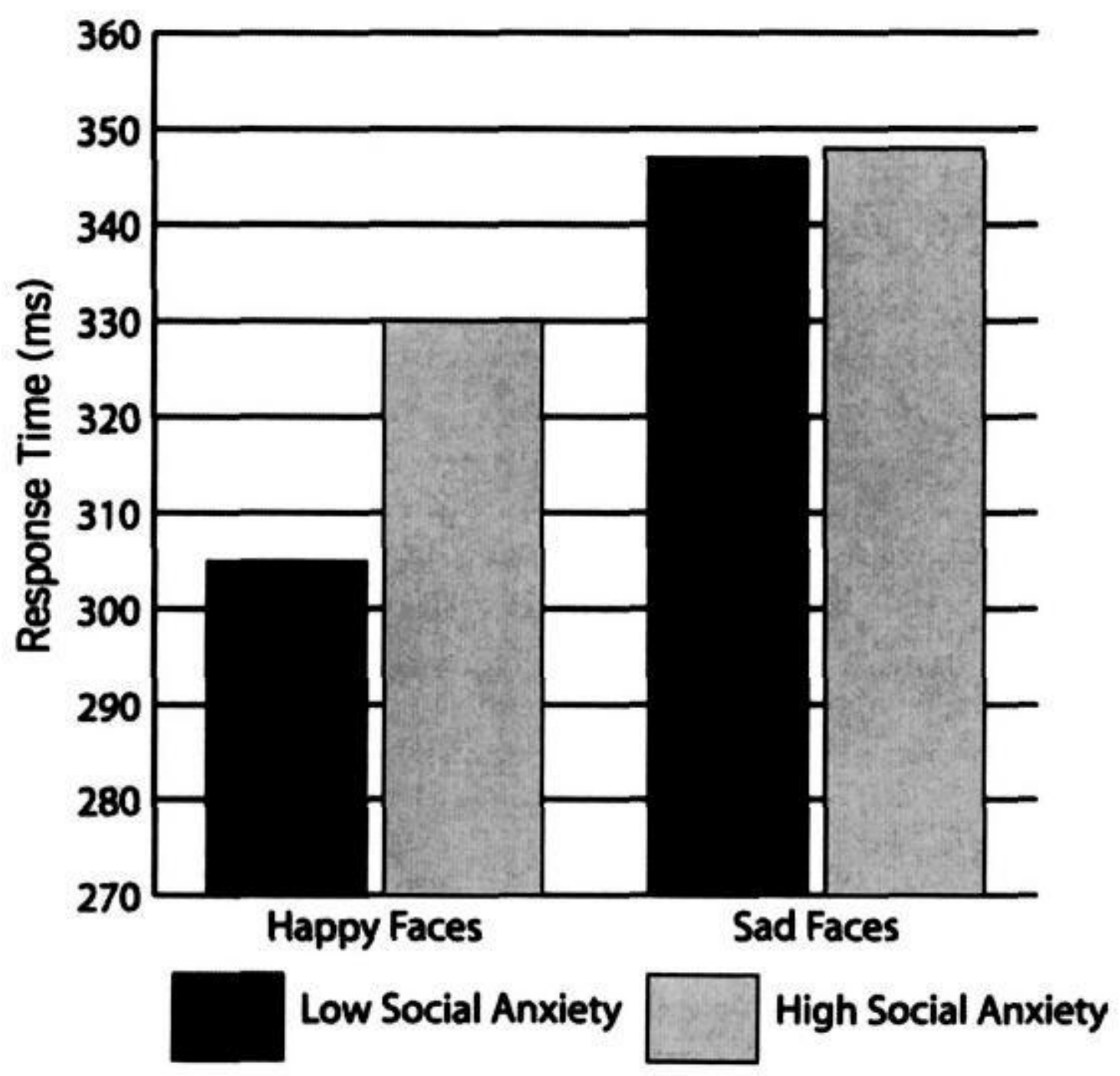

\section{FIGURE 1. Effects of social anxiety on the recognition of happy and sad faces: Experiment 1.}

\section{Analysis of Errors}

A mixed-model ANOVA estimated the effect of social anxiety (low, high) and face type (happy, sad) on errors. This analysis revealed only a significant main effect of face type, $\mathrm{F}(1,28)=5.09, \mathrm{p}<.032$; there was no main effect of social anxiety or interaction, both Fs $<1$. The data are presented in Table 1. The main effect of face type reflected higher errors for happy faces than for sad faces, although the absolute number of errors was low for both face types.

\section{DISCUSSION}

Experiment 1 found that social anxiety moderated the recognition advantage for happy faces. People low in social anxiety showed an enhanced advantage for happy faces relative to sad faces. People high in social anxiety showed a significantly smaller happy-face advantage, although they nevertheless recognized happy faces faster than sad faces. They did not recognize happy and sad faces equally quickly, nor did they show an advantage for sad faces. The effect of social anxiety on the happy-face recognition advantage thus stemmed from slower happy-face recognition, not from faster sad-face recognition (see Figure 1).

\section{EXPERIMENT 2}

The goal of Experiment 2 was to replicate and extend our examination of the effects of social anxiety on the recognition of happy faces. Experiment 2 replaced the set of sad faces with angry faces. Angry faces are 
powerful social signals because they communicate another person's hostile and threatening intentions (Darwin, 1872/1998). Research has found that angry faces have strong effects on the grabbing and holding of attention

(Fox et al., 2000, 2001; Lundqvist et al., 1999; Tipples et al., 2002). Moreover, social anxiety affects vigilance for angry faces (Mogg \& Bradley, 2002; Mogg et al., 2004). Angry faces are thus especially interesting to consider in relation to happy faces.

Participants completed a two-choice expression-recognition task, following the procedure of Experiment 1, in which they had to recognize happy faces and angry faces. As before, we expected that social anxiety would influence the recognition advantage for happy faces. People low in social anxiety should show a strong happyface advantage, and people high in social anxiety should show a smaller happy-face advantage.

\section{METHOD}

\section{Participants and Design}

A total of 27 undergraduate students (21 women and 6 men) enrolled in General Psychology at the University of North Carolina at Greensboro participated and received credit toward a research option. Women and men were evenly distributed in the low (11 women, 3 men) and high (10 women, 3 men) social-anxiety conditions.

\section{Procedure}

Participants were selected using the same procedure as Experiment 1. People in the high social-anxiety condition had elevated, but subclinical, scores on the SIAS and SPS (SIAS M = 4.42, SPS M = 3.80, on 7-point scales) relative to people in the low-social-anxiety condition (SIAS M $=1.77$,SPS $M=1.52$ ). 


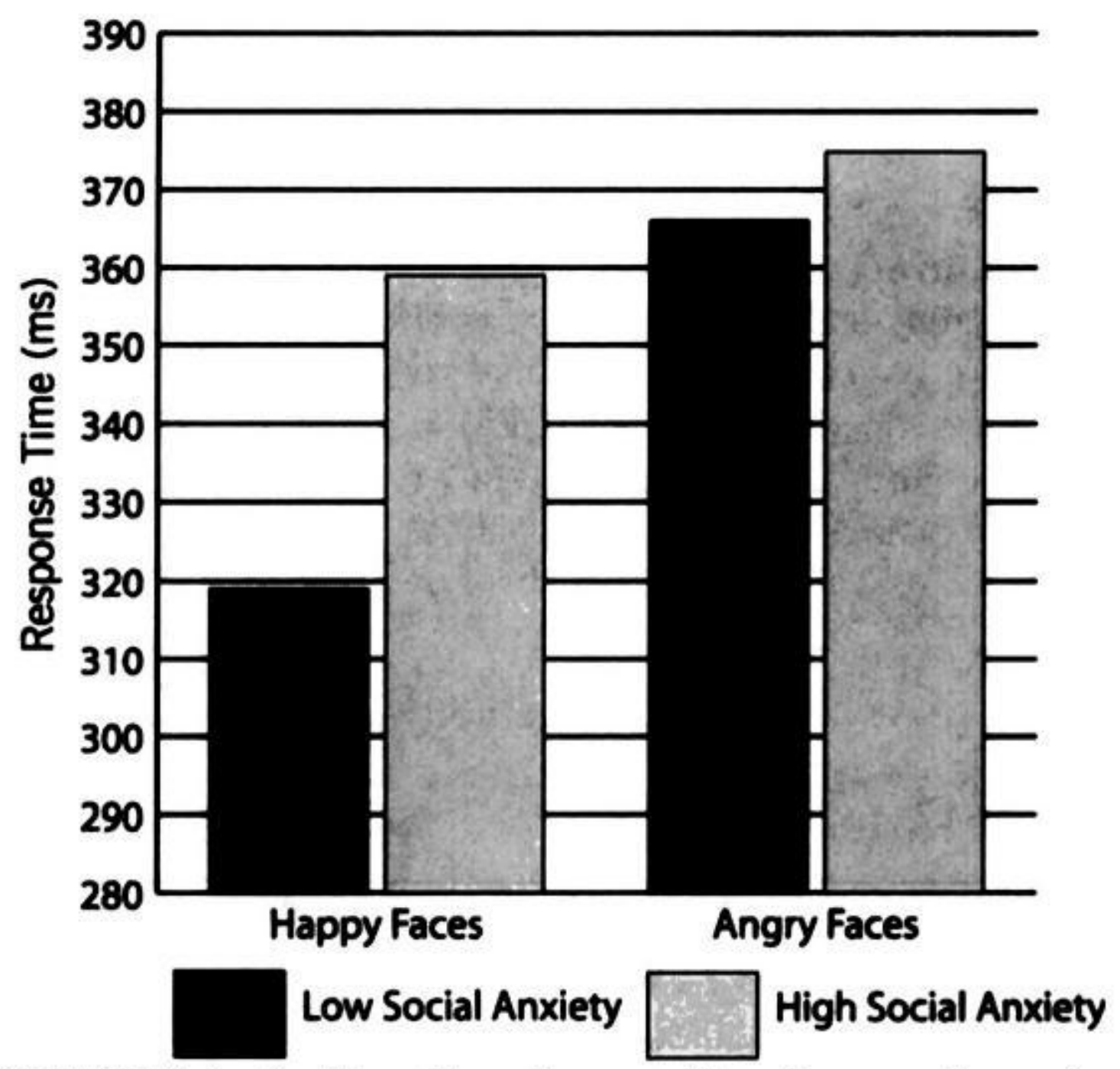

FIGURE 2. Effects of social anxiety on the recognition of happy and angry faces: Experiment 2.

\section{Recognizing Happy and Angry Faces}

In the sample as a whole, people recognized happy faces $(338 \mathrm{~ms})$ faster than angry faces (370 ms), pairedsamples $\mathrm{t}(26)=4.39, \mathrm{p}<.001, \mathrm{~d}=.84$. A mixed-model analysis of variance (ANOVA) estimated the effect of social anxiety (low, high) and face type (happy, angry) on response latencies. This analysis revealed a significant main effect of face type, reflecting the advantage for happy faces, $\mathrm{F}(1,25)=21.7$, $\mathrm{p}<.001$, as well as a significant interaction, $F(1,25)=5.42, \mathrm{p}<.028$. There was no main effect of social anxiety, $\mathrm{F}<1$. The data are presented in Table 2 and Figure 2.

Further analyses found that both groups showed a significant happy face advantage. People low in social anxiety recognized happy faces faster than angry faces, paired-samples $t(13)=4.57, p<.001, d=1.22$, with a difference of $47 \mathrm{~ms}$. People high in social anxiety recognized happy faces marginally faster than angry faces, paired-samples $\mathrm{t}(12)=1.84, \mathrm{p}<.09, \mathrm{~d}=.51$; the difference between happy and angry faces was only a third as large (16 ms). As expected, the low social-anxiety group had a significantly larger happy-face advantage relative to the high social-anxiety group, $\mathrm{t}(25)=2.33, \mathrm{p}<.028, \mathrm{~d}=.91$.

Analyses of responses to the perceptual-matching task found no differences between the high (518 ms) and low $(522 \mathrm{~ms})$ social anxiety groups, $\mathrm{f}(25)=.09, \mathrm{~ns}, \mathrm{~d}=.03$. This finding indicates that social anxiety did not cause a general impairment of performance. 
A mixed-model ANOVA estimated the effect of social anxiety (low, high) and face type (happy, angry) on errors. This analysis revealed a marginal main effect of face type, $F(1,25)=3.87, \mathrm{p}<.06$, and a marginal interaction between social anxiety and face type, $\mathrm{F}(1,25)=3.18, \mathrm{p}<.087$. There was no main effect of social anxiety, $\mathrm{F}<1$. The data are presented in Table 2. As in Experiment 1, the absolute number of errors was low overall.

\section{DISCUSSION}

Experiment 2 replicated the findings of Experiment 1 and extended the findings to angry faces, which have been shown to be particularly salient in disordered cognitive processes (e.g., Mogg et al., 2004). People low in social anxiety recognized happy faces significantly faster than angry faces; people high in social anxiety recognized happy faces marginally faster than angry faces. As before, the advantage for happy faces was significantly higher-and three times as long-in the low social anxiety condition. The pattern of findings was thus replicated. It is interesting that people high in social anxiety did not show a recognition advantage for angry faces over happy faces, even though socially anxious people are vigilant for angry faces (Mogg \& Bradley, 2002). As before, the smaller advantage for happy faces stemmed from a deficit in recognizing happy faces, not from an accelerated recognition of angry faces (see Figure 2).

\section{GENERAL DISCUSSION}

\section{BIASED RECOGNITION OF HAPPY FACES}

Although cognitive biases in social anxiety have been extensively researched (Amir \& Foa, 2001; Heinrichs \& Hoffman, 2001), one possible bias-the recognition of emotional expressions-has received little attention (Melfsen \& Florin, 2002; Winton et al., 1995). The present experiments thus examined the role of social anxiety in the recognition of happy faces. Past research has found that people reliably recognize happy faces faster than various negative emotional faces (Feyereisen et al., 1986; Kirita \& Endo, 1995; Leppanen \& Hietanen, 2003, 2004; Leppänen et al., 2003). The present experiments assessed whether people high and low in subclinical social anxiety differed in the recognition advantage for happy faces.

In both experiments, the happy-face recognition advantage stemmed from differences in happy faces instead of differences in negative faces. Relative to people low in social anxiety, people high in social anxiety did not take longer to recognize sad or angry faces. Instead, they took longer to recognize happy faces. This finding is consistent with the explanation offered by Leppànen and Hietanen $(2003,2004)$, who traced the effect to the accessibility of emotional information. Whereas nonanxious people typically view others as sources of reward and expect positive interactions (Baumeister \& Leary, 1995; Fleeson, Malanos, \& Achille, 2002), socially anxious people view others as critical and threatening (Clark \& Wells, 1995). As a result, for socially anxious people, positive emotional information about other people should be harder to retrieve and apply to face representations during the recognition task.

Based on this explanation, one could predict circumstances in which socially anxious people would show a recognition advantage for angry, disgusted, or contemptuous faces. Activating the dysfunctional interpersonal beliefs that typify social anxiety should make that information easier to retrieve and apply to perceptual representations of emotional faces (see Adolphs, 2002). Negative information about others could be activated, perhaps by a manipulation of social threat or a public-speaking challenge (e.g., Mansell et al., 1999). Past work has found that disgusted faces are recognized faster than happy faces when disgust-relevant knowledge is activated (Leppänen \& Hietanen, 2003), so it seems likely that socially anxious people could recognize negative faces faster than happy faces when their negative social beliefs are made more accessible. Examining this possibility would be a fruitful direction for future research.

The present experiments did not contrast social anxiety with depression or general anxiety. Although such comparisons are informative, the SIAS and SPS were designed to discriminate social anxiety from anxiety and depression (Mattick \& Clarke, 1998). In ongoing research with participants from the same student population, we have found modest relations between these two scales and measures of anxiety (Beck Anxiety Inventory; 
average $r=.40$ ) and depression (Beck Depression Inventory; average $r=.34$ ). Thus, there is little reason to think that depression and anxiety acted as confounds in the present research.

Understanding emotional processing provides some insight into clinical treatments for social anxiety. Treatment programs for people with high levels of social anxiety typically include components to address emotion recognition and expression as well as social skills (Turner, Beidel, Cooley, \& Woody, 1994). For example, a client may be taught to identify the specific emotion being expressed by a person in a picture. In this study, persons with social anxiety did not show deficits in identifying happy, sad, or angry faces; that is, they did not make more errors. However, they did process happy faces slower than did non-socially anxious persons, which may indicate a tendency to discount positive feedback or to expect interactions to be unrewarding. Thus, socially anxious people may benefit from being exposed step-wise to positive emotionality. For example, they may be taught how to accept compliments graciously and to reciprocate when someone initiates a positive interaction. Cognitive techniques should accompany these activities, given that the socially anxious person is likely to discount these interactions as well as their social efficacy.

\section{EMOTION RECOGNITION AND OTHER COGNITIVE BIASES}

The present findings raise the intriguing question of how biases in expression recognition relate to other biases relevant to emotional expressions. Research on cognitive aspects of clinical disorders is probably guilty of reifying the term "cognitive biases" (Stravynski, Bond, \& Amado, 2004). Diverse cognitive processes, ranging from high-level reasoning to low-level attentional processes, have been lumped together into the category of cognitive biases. This obscures important differences between each bias as well as possible patterns of relations between the various biases. Several researchers have recently contended that research should begin examining how information-processing biases relate to each other (Dalgleish et al., 2003; Gotlib et al., 2004). Thus far, research has not been successful in finding coherence among different cognitive biases. Gotlib et al. (2004) found that three measures of bias-self-referential encoding of valenced words, a dot-probe task with emotional faces, and an emotional Stroop task-failed to correlate with each other in a clinical sample of socially anxious people. Studies of coherence in samples of anxious individuals show a similar lack of convergence (Dalgleish et al., 2003; Mogg et al., 2000).

Gotlib et al. (2004) suggested that measures of bias will correlate when they share underlying processing components. As noted earlier, the recognition of emotional expressions is involved in several emotionalprocessing biases, such as the direction of attention to emotional faces (Mogg et al., 2004), memory for emotional faces (D'Argembeau et al., 2003), and avoiding emotional faces (Mansell et al., 1999). As a result, expression recognition appears to be a general processing component that is implicated in a class of cognitive biases. It thus shows promise as the type of shared mechanism that would lead to the convergence of measures of bias. If socially anxious people have biases in expression recognition, a process that undergirds other biases, then deficits in expression recognition might cascade into subsequent processing of the expression, such as the allocation of attention to and away from the face. Relating biases in face recognition to other cognitive biases is thus an important goal for future research.

\section{REFERENCES}

Adolphe, R. (2002). Recognizing emotion from facial expressions: Psychological and neurological mechanisms. Behavioral and Cognitive Neuroscience Reviews, 1,21-61.

Amir, N., \& Foa, E. B. (2001). Cognitive biases in social phobia. In S. G. Hofmann \& P. Marten (Eds.), From social anxiety to social phobia (pp. 254-267). Boston, MA: Allyn \& Bacon.

Baumeister, R. F., \& Leary, M. R. (1995). The need to belong: Desire for interpersonal attachments as a fundamental human motivation. Psychological Bulletin, 117,497-529.

Bruce, V., \& Young, A. (1986). Understanding face recognition. British Journal of Psychology, 77, 305-327. Clark, D. M., Ehlers, A., McManus, F., Hackmann, A., Fennel), M., Campbell, H., Flower, T., Davenport, C., \& Louis, B. (2003). Cognitive therapy versus fluoxetine in generalized social phobia: A randomized placebocontrolled trial. Journal of Consulting and Clinical Psychology, 71,1058-1067. 
Clark, D. M., \& Wells, A. (1995). A cognitive model of social phobia. In R. G. Heimberg, M. R. liebowitz, D. A. Hope, \& F. R. Schneier (Eds.), Social phobia (pp. 69-93). New York: Guilford Press.

Dalgleish, T., Taghavi, R., Neshat-Doost, H., Moradi, A., Canterbury, R., \& Yule, W. (2003). Patterns of processing bias for emotional information across clinical disorders: A comparison of attention, memory, and prospective cognition in children and adolescents with depression, generalized anxiety, and posttraumatic stress disorder. journal of Clinical Child and Adolescent Psychology, 32,10-21.

D'Argembeau, A., Van der Linden, M., Etienne, A., \& Comblain, C. (2003). Identity and expression memory for happy and angry faces in social anxiety. Acta Psychologica, 114, 1-15.

Darwin, C. (1872/1998). The expression of the emotions in man and animals (3rd éd.). New York: Oxford University Press.

Eastwood, J. D., Smilek, D., \& Merikle, P. M. (2001). Differential attentional guidance by unattended faces expressing positive and negative emotion. Perception and Psychophysics, 65,352-358.

Eastwood, J. D., Smilek, D., \& Merikle, P. M. (2003). Negative facial expression captures attention and disrupts performance. Perception and Psychophysics, 65,352-358.

Ekman, P. (1993). Facial expression and emotion. American Psychologist, 48,384-392.

Ekman, P., \& Friesen, W. V. (1976). Pictures of facial affect. PaIo Alto, CA: Consulting Psychologists Press. Fenske, M. J., \& Eastwood,]. D. (2003). Modulation of focused attention by faces expressing emotion:

Evidence from flanker tasks. Emotion, 3,327-343.

Feyereisen, P., Malet, C., \& Martin, Y. (1986). Is the faster processing of expressions of happiness modalityspecific? In H. D. Ellis, M. A. Jeeves, F. Newcombe, \& A. Young (Eds.), Aspects of face processing (pp. 349355). Boston, MA: Martinus Nijhoff Publishers.

Fleeson, W., Malanos, A. B., \& Achille, N. M. (2002). An intraindividual process approach to the relationship between extraversion and positive affect: Is acting extraverted as "good" as being extraverted? Journal of Personality and Social Psychology, 83, 1409-1422.

Foa, E. B., Franklin, M. E., \& Kozak, M. J. (2001). Social phobia: An information-processing perspective. In S. G. Hofmann \& P. Marten (Eds.), From social anxiety to social phobia (pp. 268-280). Boston, MA: Allyn \& Bacon.

Foa, E. B., Franklin, M. E., Perry, K. J., \& Herbert, J. D. (1996). Cognitive biases in generalized social phobia. Journal of Abnormal Psychology, 105,433-439.

Forster, K. I. (1980). Absence of lexical and orthographic effects in a same-different task. Memory and Cognition, 8,210-215.

Fox, E., Lester, V., Russo, R., Bowles, R. J., Pichler, A., \& Dutton, K. (2000). Facial expressions of emotion: Are angry faces detected more efficiently? Cognition and Emotion, U, 61-92.

Fox, E., Russo, R., Bowles, R., \& Dutton, K. (2001). Do threatening stimuli draw or hold visual attention in subclinical anxiety? Journal of Experimental Psychology: General, 130, 681-700.

Furmark, T. F., Tillfors, M., Everz, P. O., Marteinsdottir, I., Gefvert, O., \& Fredrickson, M. (1999). Social phobia in the general population: Prevalence and sociodemographic profile. Social Psychiatry and Psychiatric Epidemiology, 34,416-424.

Gilboa-Schechtman, E., Foa, E. B., \& Amir, N. (1999). Attentional biases for facial expressions in social phobia: The face-in-the-crowd paradigm. Cognition and Emotion, 13, 305-318.

Gotlib, I. H., Kasch, K. L., Traill, S., Joorman, J., Arnow, B. A., \& Johnson, S. L. (2004). Coherence and specificity of information-processing biases in depression and social phobia. Journal of Abnormal Psychology, 113,386-398.

Haxby, J. V., Huffman, E. A., \& Gobbini, M. I. (2000). The distributed human neural system for face perception. Trends in Cognitive Science, 4,223-233.

Heimberg, R. G., Mueller, G. P., Holt, C. S., Hope, D. A., \& liebowitz, M. R. (1992). Assessment of anxiety in social interaction and being observed by others: The Social Interaction Anxiety Scale (SIAS) and the Social Phobia Scale (SPS). Behavior Therapy, 23, 53-73.

Heinrichs, N., \& Hofmann, S. G. (2001). Information processing in social phobia: A critical review. Clinical Psychology Review, 21,751-770.

Herbert, J. D., Rheingold, A. A., \& Brandsma, L. L. (2001). Assessment of social anxiety and social phobia. In S. G. Hofmann \& P. Marten (Eds.), From social anxiety to social phobia (pp. 20-45). Boston, MA: Allyn \& 
Bacon.

Izard, C. E. (1971). The face of emotion. New York: Appleton-Century-Crofts.

Kashdan, T. B. (2002). Social anxiety dimensions, neuroticism, and the contours of positive psychological functioning. Cognitive Therapy and Research, 26,789-810.

Kashdan, T. B., \& Roberts, J. E. (2004). Trait and state curiosity in the genesis of intimacy: Differentiation from related constructs. Journal of Social and Clinical Psychology, 23, 792-816.

Keltner, D., \& Ekman, P. (2000). Facial expression of emotion. In M. Lewis \& J. M. Haviland-Jones (Eds.), Handbook of emotions (2nd éd., pp. 236-249). New York: Guilford Press.

Kessler, R. C., McGonagle, K. A., \& Zhao, S. (1994). Lifetime and 12-month prevalence of DSM-III-R psychiatric disorders in the United States: Results from the National Comorbidity Survey. Archives of General Psychiatry, 51,8-19.

Kirita, T., \& Endo, M. (1995). Happy face advantage in recognizing facial expressions. Acta Psychologica, 89,149-163.

Leary, M. R., \& Kowalski, R. M. (1995). Social anxiety. New York: Guilford Press.

Leppänen, J. M., \& Hietanen, J. K. (2003). Affect and face perception: Odors modulate the recognition advantage of happy faces. Emotion, 3,315-326.

Leppänen, J. M., \& Hietanen, J. K. (2004). Positive facial expressions are recognized faster than negative facial expressions, but why? Psychological Research, 69,22-29.

Leppänen, J. M., Milders, M., Bell, J. S., Terriere, M., \& Hietanen, J. K. (2004). Depression biases the recognition of emotionally neutral faces. Psychiatry Research, 128,123-133.

Leppänen, J. M., Tenhunen, M., \& Hietanen, J. K. (2003). Faster choice-reaction times to positive than to negative facial expressions. Journal ofPsychophysiology, 17,113-123.

Lundh, L., \& Öst, L. (1996). Recognition bias for critical faces in social phobies. Behaviour Research and Tlierapy, 34,787-794.

Lundqvist, D., Esteves, F., \& Ohman, A. (1999). The face of wrath: Critical features for conveying facial threat. Cognition and Emotion, 13,691-711.

Mansell, W., Clark, D. M., Ehlers, A., \& Chen, Y. (1999). Social anxiety and attention away from emotional faces. Cognition and Emotion, 33,673-690.

Mattick, R. P., \& Clarke, J. C. (1998). Development and validation of measures of social phobia scrutiny fear and social interaction anxiety. Behaviour Research and Therapy, 36, 455-470.

McNeil, D. W. (2001). Terminology and evolution of constructs in social anxiety and social phobia. In S. G. Hofmann \& P. Marten (Eds.), From social anxiety to social phobia (pp. 8-19). Boston, MA: Allyn \& Bacon. Melfsen, S., \& Florin, I. (2002). Do socially anxious children show deficits in classifying facial expressions of emotions? Journal of Nonverbal Behavior, 26,109-126.

Merckelbach, H., van Hout, W., van den Hout, M. A., \& Mersch, P. P. (1989). Psychophysiological reactions of social phobies and normals to facial stimuli. Behaviour Research and Therapy, 27,289-294.

Mogg, K., \& Bradley, B. P. (2002). Selective orienting of attention to masked threat faces in social anxiety. Behaviour Research and Therapy, 40,1403-1414.

Mogg, K., Bradley, B. P., Dixon, C., Fisher, S., Twelftree, H., \& McWilliams, A. (2000). Trait anxiety, defensiveness and selective processing of threat: An investigation using two measures of attentional bias. Personality and Individual Differences, 28, 1063-1077.

Mogg, K., Philtppot, P., \& Bradley, B. P. (2004). Selective attention to angry faces in clinical social phobia. Journal of Abnormal Psychology, 113,1600 -165.

Morse, D. T. (1999). MINSIZE2: A computer program for determining minimum sample size for statistical significance for univariate, multivariate, and nonparametric tests. Educational and Psychological Measurement, 59,518-531.

Osman, A, Gutierrez, P. M., Barrios, F. X., Kopper, B. A, \& Chiros, C. E. (1998). The Social Phobia and Social Interaction Anxiety Scales (SPS; SIAS): Evaluation of psychometric properties, Journal of Psychopathology and Behavioral Assessment, 20, 249-264.

Philippot, P., \& Douilliez, C. (2005). Social phobies do not misinterpret facial expressions of emotion.

Behaviour Research and Therapy, 43,639-652.

Procter, R. W., \& Rao, K. V. (1983). Evidence that the same-different disparity in letter matching is not 
attributable to response bias. Perception and Psychophysics, 34,72-76.

Rapee, R. M., \& Heimberg, R. G. (1997). A cognitive-behavioral model of anxiety in social phobia. Behaviour Research and Therapy, 35,741-756.

Ratcliff, R. (1993). Methods for dealing with reaction time outliers. Psychological Bulletin, 114,510-532.

Ratcliff, R., \& Hacker, M. J. (1981). Speed and accuracy of same and different responses in perceptual matching. Perception and Psychophysics, 30,303-307.

Silvia, P. J., \& Warburton, J. B. (2006). Positive and negative affect: Bridging states and traits. In D. L. Segal \& J. C. Thomas (Eds.) Comprehensive handbook of personality and psychopathology, Vol. 1 : Personality and everyday functioning (pp. 268-284). New York: Wiley.

Spurr, J. M., \& Stopa, L. (2002). Self-focused attention in social phobia and social anxiety. Clinical Psychology Review, 22,947-975.

Stenberg, G., Wiking, S., \& Dahl, M. (1998). Judging words at face value: Interference in a word processing task reveals automatic processing of affective facial expressions. Cognition and Emotion, 12,755-782.

Stravynski, A., Bond, S., \& Amado, D. (2004). Cognitive causes of social phobia: A critical appraisal. Clinical Psychology Review, 24,421-440.

Tipples, J., Atkinson, A. P., \& Young, A. W. (2002). The eyebrow frown: A salient social signal. Emotion, 2,288-296.

Turk, C. L., Lerner, J., Heimberg, R. G., \& Rapee, R. M. (2001). An integrated cognitive-behavioral model of social anxiety. In S. G. Hofmann \& P. Marten (Eds.), From social anxiety to social phobia (pp. 281-303).

Boston, MA: Allyn \& Bacon.

Turner, S. M., Beidel, D. C., Cooley, M. R., \& Woody, S. R. (1994). A multicomponent behavioral treatment for social phobia: Social effectiveness therapy. Behaviour Research and Therapy, 32,381-390.

Wacker, H. R., Müllejans, R., Klein, K. H., \& Battegay, R. (1992). Identification of cases of anxiety disorders and affective disorders in the community according to ICD-10 and DSM-III-R by using the Composite International Diagnostic Interview (CIDI). International Journal of Methods in Psychiatric Research, 2,91-100. Wallace, S. T., \& Alden, L. E. (1997). Social phobia and positive social events: The price of success. Journal of Abnormal Psychology, 106,416-424.

Winton, E. C, Clark, D. M., \& Edelmann, R. J. (1995). Social anxiety, fear of negative evaluation and the detection of negative emotion in others. Behaviour Research and Therapy, 33,193-196.

Wittchen, H. U., Stein, M. B., \& Kessler, R. C. (1999). Social fears and social phobia in a community sample of adolescents and young adults: Prevalence, risk factors, and comorbidity. Psychological Medicine, 29, 309-323. 